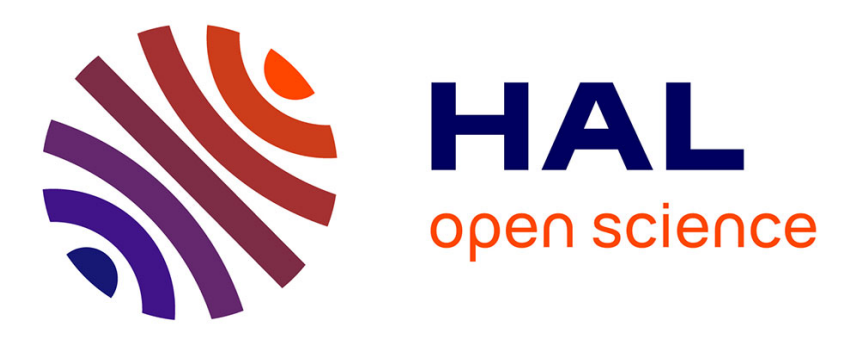

\title{
Lifetime of superheated water in a micrometric synthetic fluid inclusion
}

\author{
Mouna El Mekki, Claire Ramboz, Laurent Perdereau, Kirill Shmulovich, \\ Lionel Mercury
}

\section{- To cite this version:}

Mouna El Mekki, Claire Ramboz, Laurent Perdereau, Kirill Shmulovich, Lionel Mercury. Lifetime of superheated water in a micrometric synthetic fluid inclusion. Metastable Systems Under Pressure: Platform new technologies and environnemental applications, Oct 2008, Odessa, Ukraine. pp.279-292, 10.1007/978-90-481-3408-3 . insu-00349576

\section{HAL Id: insu-00349576 https://hal-insu.archives-ouvertes.fr/insu-00349576}

Submitted on 2 Jan 2009

HAL is a multi-disciplinary open access archive for the deposit and dissemination of scientific research documents, whether they are published or not. The documents may come from teaching and research institutions in France or abroad, or from public or private research centers.
L'archive ouverte pluridisciplinaire HAL, est destinée au dépôt et à la diffusion de documents scientifiques de niveau recherche, publiés ou non, émanant des établissements d'enseignement et de recherche français ou étrangers, des laboratoires publics ou privés. 


\title{
Lifetime of superheated water in a micrometric synthetic fluid inclusion
}

SUPERHEATING LIFETIME

\author{
MOUNA EL MEKKI', \\ CLAIRE RAMBOZ, \\ LAURENT PERDEREAU ${ }^{1}$, \\ KIRILL SHMULOVICH ${ }^{2}$, \\ LIONEL MERCURY ${ }^{1}$ \\ ${ }^{1}$ Université d'Orléans-Tours, UMR 6113 CNRS-INSU et Institut des \\ Sciences de la Terre d'Orléans, lA mie de la Férollerie, 45071 Orléans, \\ France. \\ ${ }^{2}$ Institute of Experimental Mineralogy, Russian Academy of Science, \\ 142432 Chernogolovka, Russia
}

\begin{abstract}
A synthetic pure water fluid inclusion presenting a wide temperature range of metastability $\left(\mathrm{Th}-\mathrm{Tn} \approx 50^{\circ} \mathrm{C}\right.$; temperature of homogenization $\mathrm{Th}=$ $144^{\circ} \mathrm{C}$ and nucleation temperature of $\mathrm{Tn}=89^{\circ} \mathrm{C}$ ) was selected to make a kinetic study of the lifetime of an isolated microvolume of superheated water. The occluded liquid was placed in the metastable field by isochoric cooling and the duration of the metastable state was measured repetitively for 7 fixed temperatures above Tn. Statistically, measured metastability lifetimes for the 7 data sets follow the exponential Reliability distribution, i.e., the probability of non nucleation within time t equals $e^{-\lambda t}$. This enabled us to calculate the half-life periods of metastability $\tau$ for each of the selected temperature, and then to predict $\tau$ at any temperature $\mathrm{T}>\mathrm{Tn}$ for the considered inclusion, according to the equation $\tau(\mathrm{s})=22.1 \times e^{-1.046 \times \Delta T},(\Delta \mathrm{T}=\mathrm{T}-\mathrm{Tn})$. Hence we conclude that liquid water in water-filled reservoirs with an average pore size $\approx 10^{4} \mu \mathrm{m}^{3}$ can remain superheated over geological timelengths $\left(10^{7} \mathrm{~s}\right)$, when placed in the metastable field at $10^{\circ} \mathrm{C}$ above the average nucleation temperature, which often corresponds to high liquid tensions $(\approx-120-70 \mathrm{MPa})$.
\end{abstract}

Key Words: microthermometry, experimental kinetics, microvolumes, pure water, natural systems

\section{Introduction}

Any liquid can experience three thermodynamic states with regard to the phase diagram: stable, metastable, and unstable. When metastable with respect to its vapour, the so-called superheated liquid persists over the more stable vapour owing to the nucleation barrier related to the cost to create the liquid-vapour interface. Practically speaking, a superheated liquid undergoes any P-T conditions located between the saturation and the spinodal curves (Fig. 1). It should be noted that the term "superheating" does not refer to a particular range of temperature, and goes down to temperatures in the melting area. This 
superheat metastability gives to the liquid a certain "overstability feature" with respect to vapour. Indeed, geologists have long observed that liquid water displays such overstability in certain low and high temperature contexts. For instance, the soil capillary water ${ }^{1}$ or the water state in very arid environments like the Mars surface ${ }^{2,3}$ are natural examples of low $\mathrm{T}$ superheated liquid states whereas certain continental and submarine geysers ${ }^{4}$ or the deep crustal rocks ${ }^{5}$ can also generate high $\mathrm{T}$ superheated solutions.

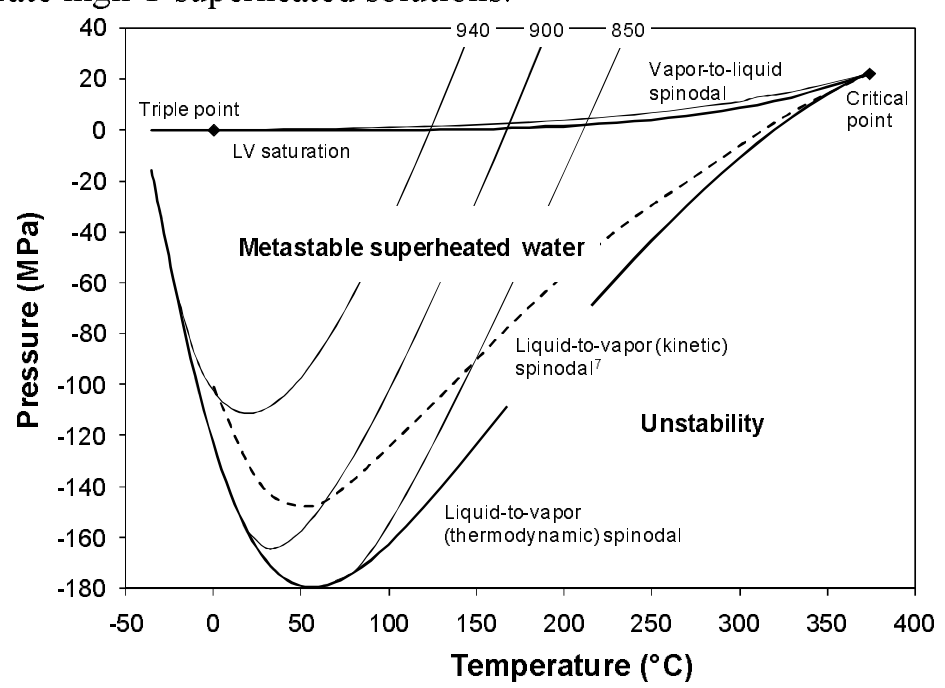

Fig. 1 Pure water phase diagram in $(\mathrm{P}, \mathrm{T})$ coordinates, calculated from the IAPWS-95 equation of state ${ }^{6}$, extrapolated at negative liquid pressures in the superheat domain. The outer lines starting from the critical point are the thermodynamic limits of metastability (spinodal). The dotted line is one proposed kinetic metastability limit ${ }^{7}$. Three isochoric lines $\left(950,900\right.$ and $\left.850 \mathrm{~kg} \mathrm{~m}^{-3}\right)$ are also calculated by extrapolation of the IAPWS-95 equation.

The shape of the pure water spinodal has long been a matter of debate in the physics community. To date, three competing scenarios are proposed, one with the retracing shape towards positive pressure at low temperatures, the two others with a monotonous decreasing shape. The first model relates to the stability-limit conjecture $^{8}$ based on experimental data on supercooled water. It can be demonstrated $^{9}$ that the retracing shape corresponds to the intersection of the spinodal curve with the Temperature of Maximal Density (TMD) line. The second proposed scenario derives from molecular simulation ${ }^{10}$ and predicts a constant positive slope, hence a spinodal monotonously extending towards negative pressures. Thermodynamically, it implies that the slope the TMD changes from negative to positive. The experimental data previously mentioned are here interpreted as related to the presence of a second critical point at low temperature and positive pressure ${ }^{10,11}$. The third proposition is the singularity-free hypothesis $^{12}$, associating a non-retracing spinodal with thermodynamic divergences. In this model, all the polyamorphic transitions of liquid water at low temperature are just relaxation phenomena and not real phase transitions, referring explicitly in that respect to the percolation mode $1^{13}$. It is worth noting 
that most equations of state (EOS) like the van der Waals equation or the IAPWS-95 EOS result in the retracing behaviour when extrapolated in the metastable field (Fig. 1). Obviously, this is not at all an argument in support of the latter conception. However, we want to highlight that our experimental investigations are not concerned for the time being with the low temperature superheating region, so that our calculations are not influenced by this debate. The problem of the extrapolative capability of the IAPWS-95 equation remains but it seems to be satisfying enough as already discussed elsewhere ${ }^{14-16}$.

\section{Scientific context}

The chosen experimental technique to investigate the metastability liquid field is to submit to heating-cooling cycles micrometric volumes of fluid trapped in a solid fragment ${ }^{14}$. This method allows measurement of the nucleation temperature (Tn) of every fluid inclusion (FI) in the host crystal, which is an evaluation of the extreme metastability that the given intracrystalline liquid can undergo before breaking instantaneously (over the experimental time, this occurs within some tenth of seconds). By this method, the extreme tensile strength of one specific liquid (pure water, aqueous solutions...) can be directly recorded. Previous measurements provided evidences that water and in general aqueous solutions can reach very high degrees of metastability (tension reaching hundreds of $\mathrm{MPa})^{14,17-20}$. As a matter of fact, every inclusionnist (geologist dealing with fluid inclusions) is faced to the superheating ability of these micrometric fluid systems, which appears in general as a nuisance as it prevents further measurements of phase equilibria. On the other hand, a superheated liquid experiencing properties in the stretched state (negative pressure domain) displays specific thermodynamic properties. Hence distinctive solvent properties can be expected as compared to bulk water. As an example, in the Red Sea, the abnormal thermal balance of the Atlantis II Deep lower brine ${ }^{4}$ has been accounted for by an influx of hypercaloric superheated brines ${ }^{4,21}$.

As noted above, a metastable liquid can be superheated to a very high degree before nucleating a vapour instantaneously. In kinetic terms, this means that the nucleation energetic barrier is of the same order of magnitude as the thermal energy $\mathrm{kT}$ of the system. This spontaneous nucleation limit is sometimes called the kinetic spinodal ${ }^{7}$ (Fig. 1). When one goes towards PT pairs above the kinetic spinodal, the nucleation barrier becomes greater than the thermal energy and the lifetime becomes longer. Generally speaking, the Classical Nucleation Theory (CNT) tells us that the nucleation rate of vapour bubble follows an Arrhenius law ${ }^{22}$ :

$$
J=J_{0} \times e^{-\frac{E_{0}}{k T}}
$$

where $\mathrm{J}$ is the number of nuclei per unit volume per unit time, $J_{0}$ is a kinetic prefactor, $E_{b}$ is the nucleation energy barrier related to the energy of interface creation. 
The nucleation barrier is easy to formulate considering that the created gas-liquid interface related to bubble nucleation increases the system energy by $2 \pi \mathrm{r}^{2} \gamma(\mathrm{r}$ is the radius of the spherical bubble, and $\gamma$ is the liquid-vapour surface tension), while the formation of the most stable phase provides bulk energy $\left(4 / 3 \pi r^{3} \Delta P\right.$, with $\Delta \mathrm{P}=\mathrm{P}_{\text {LIQUID }}-\mathrm{P}_{\mathrm{VAPOUR}}$ ). According to the $\mathrm{CNT}$, the competition between these two opposite effects results in an energy barrier $\mathrm{E}_{\mathrm{b}}{ }^{22}$ :

$$
E_{b}=\frac{16 \pi}{3 \gamma^{3} \Delta P^{2}}
$$

$E_{b}$ is reached when the spherical bubble reaches a critical radius $r_{c}=\frac{2 \gamma}{\Delta P}$.

According to (1), $\mathrm{P}$, the probability of nucleation in a volume $\mathrm{V}$ and during a given timelength $t$ is:

$$
\mathrm{P}=1-e^{-J V t}
$$

Nucleation is assumed to occur when $P=0.5$. Then, the half-life period $\tau$ (median value of duration) required to get at least one vapour nucleus is :

$$
\tau=\frac{\operatorname{Ln}(2)}{J V}
$$

Thus, the time necessary to create a bubble nucleus is inversely proportional to the fluid volume. In other words, if one second is sufficient to create one nucleus in a volume of 1 litre, more than 11 days are required in a volume of $1 \mathrm{~mm}^{3}$. Statistically, almost 32000 years are necessary to do so in a volume of $1000 \mu \mathrm{m}^{3}$, a typical size for interstitial pores in most natural porous media. This calculation is made at constant $\mathrm{J}$, namely for a given value of $\mathrm{E}_{\mathrm{b}}$, i.e., at constant metastable "intensity" and heterogeneous nucleation conditions (due to impurities in the liquid or to solid surface singularities). Thus, at constant physico-chemical conditions, nucleation is an event that becomes rarer as the fluid container is smaller. This is why soil scientists recently proposed that capillarity can occur without meeting the Laplace condition, and so capillary water and its special superheating properties can occur in the whole range of microporosity, thus affecting rather large amounts of soil water ${ }^{1}$.

The consequences of superheating in natural systems are twice. In contexts of high thermal anomalies (geyser, phreato-magmatism), the changes in the fluid properties at the nucleation event (relaxation of the superheating features) may have drastic physical consequences: rapid volume changes at the phase transition, potentially accompanied by deep changes in fluid speciation. This implies explosivity and massive solid precipitation (or massive dissolution depending on the role of superheating on the rock-solution equilibria). In dry environments, superheating is a long-lived process controlled by the aridity of the atmosphere (soil capillarity). The rock-water-gas interactions thus involve a superheated liquid component which modifies the chemical features of the resident solutions ${ }^{1}$. Whatever the superheating context, once a natural system becomes metastable, its effective influence will depend on the duration of the metastable state, as both chemical and heat exchanges also require long time to be fully achieved. 
Sample. The fluid inclusion chosen in this study was selected among the ones previously synthetized to investigate the extreme tensile strength of liquids, depending on composition and density ${ }^{14}$. Our experimental procedure is similar to that adopted in a previous paper ${ }^{23}$. The selected inclusion was placed in a superheated state at a given $\mathrm{T}>\mathrm{Tn}$ by isochoric cooling, then we waited for the bubble to nucleate. Different intensities of liquid stretching were tested, as the same experiment was performed at 7 different temperatures above $\mathrm{Tn}$. Note that Tn fixes the maximum stretching intensity sustainable by the selected inclusion. According to the CNT and as confirmed by previous experiments ${ }^{23}$, the distribution of metastability lifetimes is expected to display an exponential decrease.

The chosen fluid inclusion ( $n^{\circ} 31-7$ ) is located in a $450 \mu$ m-thick quartz fragment and is located $77 \mu \mathrm{m}$-deep below the crystal surface. It is quite big, 64- $\mu \mathrm{m}$ long and $20 \mu \mathrm{m}$-wide (estimated volume $\approx 8600 \mu \mathrm{m}^{3}$ ) with a long appendix indicating a process of necking down (Fig. 2).

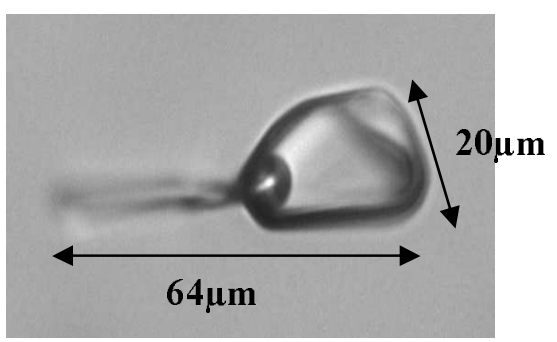

Fig. 2 Microphotograph of the studied pure water synthetic fluid inclusion (x50).
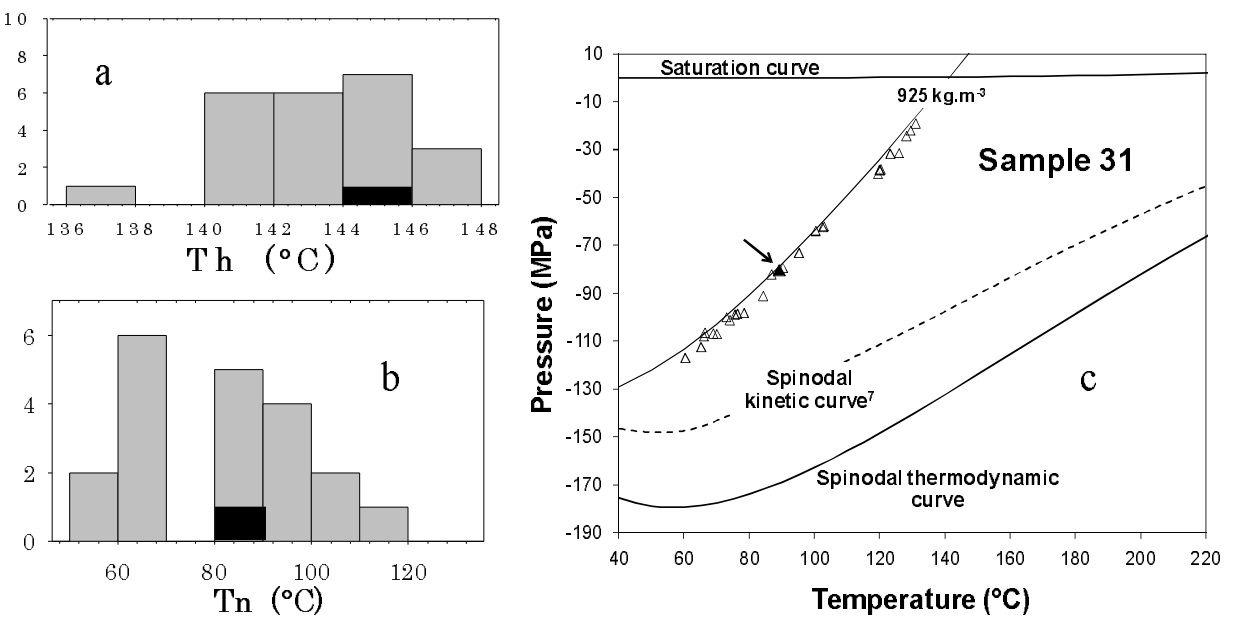

Fig. 3 Properties of sample 31 pure water fluid inclusions. Figs 3a and 3b: Distribution of Th and Tn measurements. Fig. 3c: PT conditions of nucleation of sample 31 inclusions (triangles), with the average corresponding isochore $\left(\mathrm{d}=925 \mathrm{~kg} \mathrm{~m}^{-3}\right)$ extrapolated in the metastable field. The PT pure water phase diagram, the isochore and data points are calculated after IAPWS-95 EOS ${ }^{6}$. The dark areas and arrow indicate the position of the studied $n^{\circ} 31-7$ inclusion (see text) 
This inclusion belongs to quartz sample 31 , which contains pure water synthetic inclusions with an average density of $925 \mathrm{~kg} \mathrm{~m}^{-3}$. Note that as quartz is incompressible below $300^{\circ} \mathrm{C}$, the PT path followed by the inclusion fluid at changing $\mathrm{T}$ is isochoric (constant mass, constant volume). The average isochoric PT path of sample 31 inclusions is shown in Figure 3, together with their representative points at $\mathrm{Tn}$. The internal pressure at $\mathrm{Tn}$ is calculated from the density-Tn measurements on extrapolating the IAPWS-95 "official" pure water EOS $^{6}$. This equation also allows to derive the thermodynamic fluid properties of pure water at given P-T pairs (see reference 14 for more details).

\section{Experimental procedure.}

Sample 31 quartz fragment was placed on a Linkam heating-cooling stage mounted on a Olympus BHS microscope. Its temperature was allowed to vary (Fig. 4). Phase changes in the inclusion were observed with a $x 50$ LWD objective and were recorded using a Marlin black and white camera (CMOS 2/3" sensor, $\approx$ 15 frames/s).

Microthermometry. The key characteristics of the studied n $31-7$ fluid inclusion are the homogenization and the nucleation temperatures (Th and $\mathrm{Tn}$, respectively). Th is the disappearance temperature of the last drop of vapour in the cavity (at $\mathrm{Th}$, the saturation conditions are met). $\mathrm{Tn}(\mathrm{Tn}<\mathrm{Th})$ is the measured temperature when the trapped metastable liquid becomes diphasic (it marks the end of the stretched metastable state). Th and Tn were measured, in that order, in the course of strictly temperature-controlled heating and cooling cycles (Th: path 1 to 4; Tn: path 4 to 6, respectively; Fig. 4).

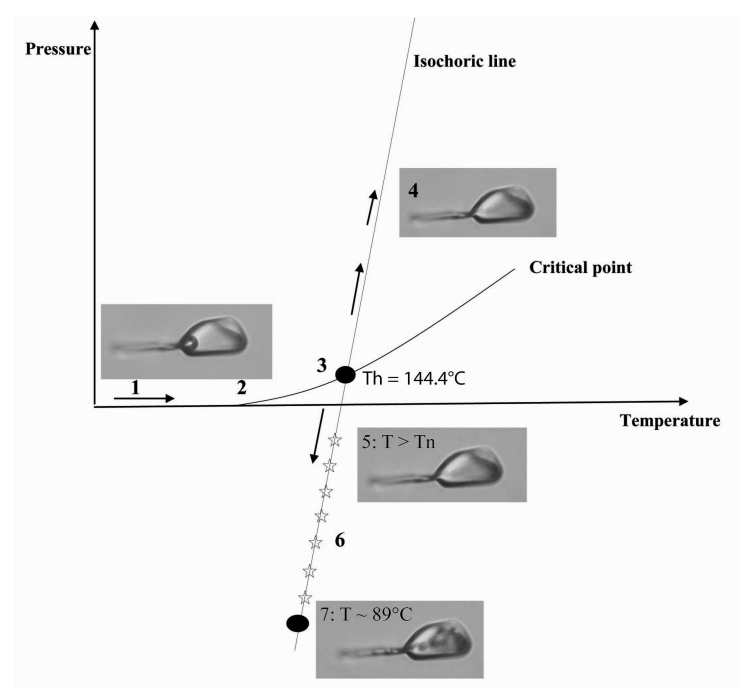

Fig. 4 PT pathways followed by a fluid inclusion heated from ambient conditions (path 1 to 4 ) then further cooled. Photomicrographs show the observed successive states of the occluded fluid. The bold curve is the saturation curve and the stars qualitatively represent the seven temperature steps chosen for the kinetic study. 
Table 1 summarizes the rates of temperature change that were adopted all along the kinetic study. A cooling rate of $2^{\circ} \mathrm{C} / \mathrm{min}$ was chosen to measure $\mathrm{Tn}$ as it offered the best conditions to observe bubble nucleation.

\begin{tabular}{|c|c|c|c|c|c|c|}
\cline { 2 - 7 } \multicolumn{1}{c|}{} & \multicolumn{4}{c|}{ Heating cycle (Th measurement) } & \multicolumn{2}{c|}{$\begin{array}{c}\text { Cooling cycle (Tn } \\
\text { measurement) }\end{array}$} \\
\hline T range $\left({ }^{\circ} \mathrm{C}\right)$ & $25-130$ & $130-140$ & $140-150$ & $150-160$ & $160-105$ & $105-80$ \\
\hline & & & $\mathrm{Th}=144.4$ & & & $\mathrm{Tn}=89$ \\
\hline $\begin{array}{c}\text { Heating/cooling } \\
\text { rate }\left({ }^{\circ} \mathrm{C} / \mathrm{mn}\right)\end{array}$ & 30 & 10 & 2 & 10 & 30 & 2 \\
\hline
\end{tabular}

Table 1: Rate-controlled sequences of heating and cooling chosen for Th and Tn measurements. First, heating along the liquid-vapour curve (diphasic inclusion), then isochoric heating followed by isochoric cooling down (single-phase inclusion).

Kinetic measurements consisted in placing inclusion $\mathrm{n}^{\circ} 31-7$ in the metastable field. The procedure was the same as for Tn measurements except that, during cooling, the inclusion was stabilized at $1^{\circ}, 1.3^{\circ}, 2^{\circ}, 3^{\circ}, 3.5^{\circ}, 4^{\circ}$ and $5^{\circ} \mathrm{C}$ above Tn, successively (stars Fig. 4). The inclusion was thus kept metastable at 7 fixed temperatures between $90.4^{\circ}$ and $94.4^{\circ} \mathrm{C}$. For each given temperature, the duration of metastability was measured repetitively (between 5 and 16 metastability lifetime measurements). The beginning of the temperature step was taken as the starting point of the experiment (time 0 ). Between each set of kinetic measurements at a fixed temperature, we checked that $\mathrm{Th}$ and $\mathrm{Tn}$ had not changed significantly.

\section{Results}

Microthermometry. At the start of the study, Th and Tn measurements of inclusion $\mathrm{n}^{\circ} 31-7$ were repeated 11 times, following the $\mathrm{T}$ procedure summarized in Table 1. Measured $\mathrm{Th}$ and $\mathrm{Tn}$ were $144.4^{\circ}$ and $88.8^{\circ} \mathrm{C}$ respectively, with a repeatability of $\pm 0.2^{\circ} \mathrm{C}$ for Th and of $\pm 2.3^{\circ} \mathrm{C}$ for $\mathrm{Tn}$. Thus the measured range of metastability for inclusion $\mathrm{n}^{\circ} 31-7$ was $54.6^{\circ} \pm 3.3^{\circ} \mathrm{C}$ (Table 2), corresponding to internal $\mathrm{P}$ conditions of $-84 \pm 4 \mathrm{MPa}$.

\begin{tabular}{c|c|c|c|c|c|c|c|c|c|c|c}
$\mathrm{T}\left({ }^{\circ} \mathrm{C}\right)$ & 1 & 2 & 3 & 4 & 5 & 6 & 7 & 8 & 9 & 10 & 11 \\
\hline \hline $\mathrm{Th}$ & 144.4 & 144.4 & 144.4 & 144.2 & 144.2 & 144.2 & 145.1 & 145.1 & 144.4 & 144.4 & 144.4 \\
\hline $\mathrm{Tn}$ & 89.8 & 89.8 & 86.5 & 86.5 & 87.0 & 87.5 & 87.5 & 89.8 & 91.2 & 87.2 & 87.2 \\
\hline $\mathrm{Th}-\mathrm{Tn}$ & 54.6 & 54.6 & 57.9 & 57.9 & 57.24 & 56.7 & 56.6 & 55.3 & 53.2 & 57.2 & 57.2
\end{tabular}

Table 2 Repetitive cycles of Th and Tn measurements.

We observed more than 50 vapour nucleation events in the FI, which enabled us to identify the main stages of cavitation. The two-phase stable situation was recovered within about $1 / 3 \mathrm{~s}$ (5 to 6 images with our camera). In general, nucleation started in the broadest part of the inclusion by a foam, a milky cloud a 
little more contrasted than the liquid. Then, a burst of tiny bubbles, taking birth in the inclusion appendix, invaded the whole cavity (microphotograph 7, Fig. 4).

Kinetic results. Figure 5 shows the distribution of kinetic measurements for 7 temperature steps between $90.4^{\circ}$ and $94.4^{\circ} \mathrm{C}$ (duration times in logarithmic scale).
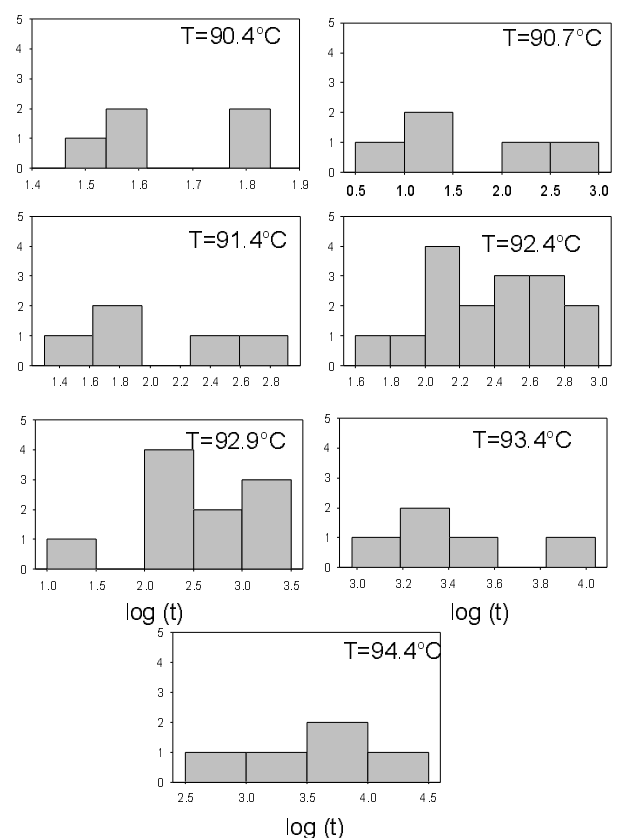

Fig. 5 Distribution of the measured metastability lifetimes (s) of inclusion $n^{\circ} 31-7$ (logarithmic scale) for 7 temperature steps above $\mathrm{Tn}$.

\section{Interpretation of the kinetic data sets.}

Let $T_{\text {step }}$ be the temperature above $T n$ at which inclusion $n^{\circ} 31-7$ is stabilized in the metastable liquid state. Let $t_{0}$ be the time at which the temperature step begins $\left(t_{0}\right.$ is taken as 0 ). Let $t_{i}$ be the timelength elapsed between $t_{0}$ and the vapour nucleation event $(t>0)$. The variable $t$ is continuous and characterized by a density probability function $\mathrm{f}(\mathrm{t})$ such that:

$$
\int_{0}^{\infty} f(t) d t=1
$$

According to the Classical Nucleation Theory, the repetitive formation of nuclei in a metastable liquid can be considered as a sequence of independent events and the distribution of metastable lifetimes shows an exponential decrease (see also Takahashi et $a .^{23}$ ). This implies that the density probability function $\mathrm{f}(\mathrm{t})$ of the nucleation event is:

$$
f(t)=\lambda \times e^{-\lambda t}
$$

where $\lambda$ is the exponential decay constant and $1 / \lambda$ the mean life of the metastable state. 
The probability that the vapour bubble nucleates within timelength $t$ is thus:

$$
\mathrm{P}(\mathrm{E} \leq \mathrm{t})=\int_{0}^{t} \lambda e^{-\lambda t} d t=1-e^{-\lambda t} \text { (Exponential Failure distribution) }
$$

The probability of non nucleation of the vapour bubble within timelength $t$ is

$$
\mathrm{P}(\mathrm{E}>\mathrm{t})=e^{-\lambda t} \text { (Exponential Reliability distribution) }
$$

Calculation of the decay rate $\lambda$ and half-life period $\tau$ at a fixed temperature step. At each temperature step, we have built the exponential reliability distribution, i.e., the probability of the non nucleation event within timelength $t(P(E>t)$. The $\operatorname{Ln}[\mathrm{P}(\mathrm{E}>\mathrm{t})]$ were plotted versus timelength $\mathrm{t}$ and the data were fitted by a straight line passing by the origin (Fig. 6; correlation coefficients of the fits ranging between 0.84 and 0.99 , Table 3 ).

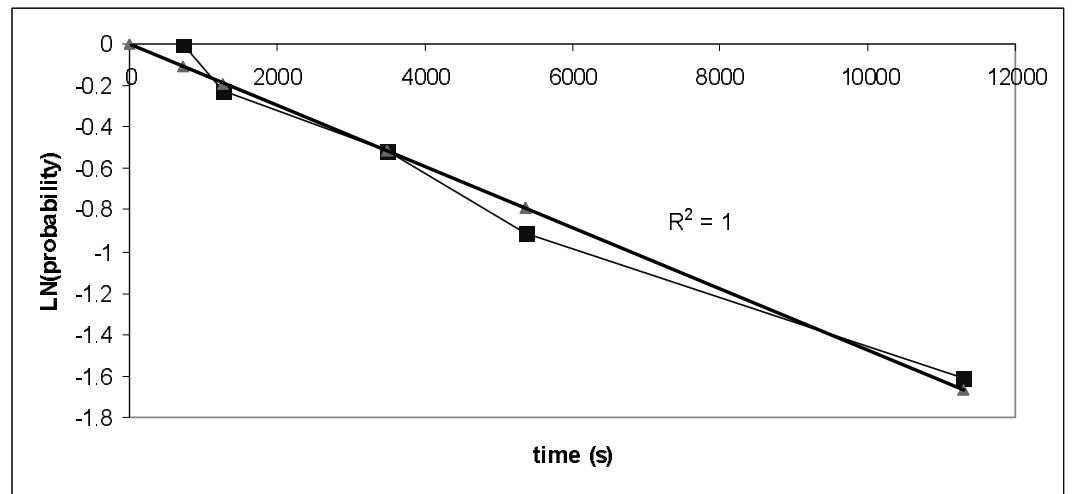

Fig. 6 Observed Fiability law at the temperature step $\mathrm{T}=94.4^{\circ} \mathrm{C}$.

Hence we derived the exponential decay constants $\lambda$ for the $7 \mathrm{~T}$-steps considered (Table 3 ). The half-life period $\tau$ at each $\mathrm{T}$ step was then calculated as follows:

$$
\tau=\frac{\operatorname{Ln}(2)}{\lambda}
$$

\begin{tabular}{c||c|c|c||}
\multirow{2}{*}{\multicolumn{1}{c||}{$\begin{array}{c}\text { Temperature } \\
\left({ }^{\circ} \mathrm{C}\right)\end{array}$}} & \multicolumn{3}{c||}{ Exponential Fiability model } \\
\cline { 2 - 4 } & $\lambda$ & $\mathrm{R}^{2}$. & $\tau$ \\
\hline \hline $90.4(5)$ & 0.0169 & 0.84 & 40.9 \\
\hline $90.7(5)$ & 0.0046 & 0.94 & 149.5 \\
\hline $91.4(5)$ & 0.0021 & 0.90 & 322.9 \\
\hline $92.4(16)$ & 0.0024 & 0.99 & 286 \\
\hline $92.9(10)$ & 0.00068 & 0.93 & 1025 \\
\hline $93.4(10)$ & 0.00059 & 0.97 & 1166 \\
\hline $94.4(5)$ & 0.000147 & 0.99 & 4702.1
\end{tabular}

Table 3 Exponential decay constants $\lambda$ calculated from the reliability distributions observed at each temperature step, and half-life periods $\tau$ related. $\mathrm{R}$ is the correlation coefficient of the linear fit of the data (see text). Number between brackets $=$ number of $\mathrm{t}$ measurements. 
On Figure 7, the calculated $\tau$ are plotted as a function of $\Delta \mathrm{T}$, the temperature distance to Tn (i.e. T-Tn). The $\tau$ values decrease exponentially as a function of $\Delta \mathrm{T}$, with a fitted decay constant close to 1 . Due to the fact that the fitted preexponential factor is different from 1 , we calculate a half-life period at Tn of about $22 \mathrm{~s}$ instead of 0 . On account of the heating rate adopted close to $\mathrm{Tn}$ (see Table 1), this indicates that the nucleation event started on average $\approx 0.7^{\circ} \mathrm{C}$ before the beginning of the temperature step during cooling, our chosen time zero. Given that the measured variability on $\mathrm{Tn}$ is $\approx 2.3^{\circ} \mathrm{C}$ (Table 2 ), these results corroborate our choice of placing the starting point of the kinetics experiment at around the beginning of the temperature step, rather than at $\mathrm{Th}$, as previously $\operatorname{proposed}^{23}$.

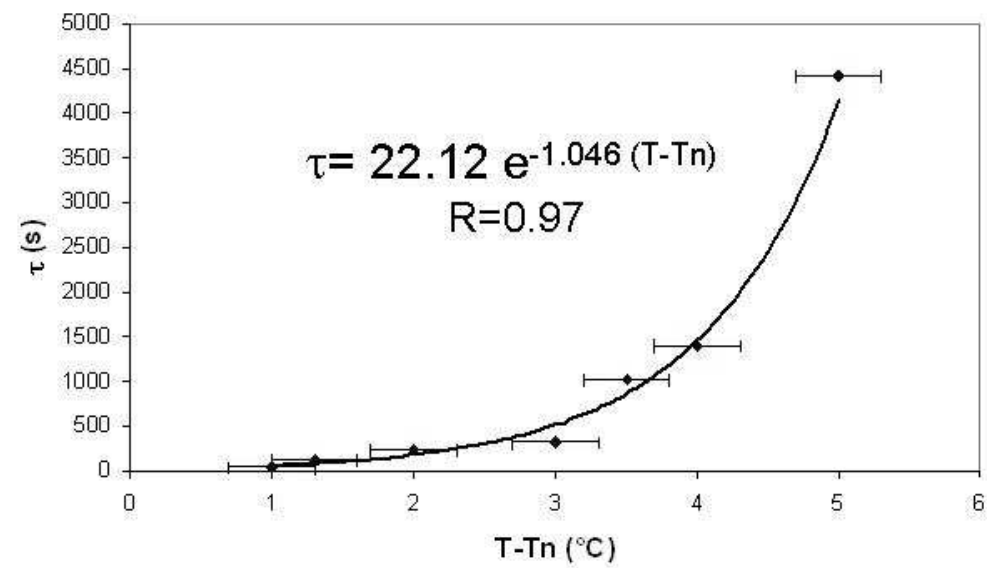

Fig. 7 Inclusion $\mathrm{n}^{\circ} 31-7$ : Half-life period of metastability as a function of the intensity of superheating (T-Tn). Tn corresponds to the maximum degree of metastability sustainable by the inclusion.

\section{Geological implications}

Our data show that at a temperature of $10^{\circ} \mathrm{C}$ above $\mathrm{Tn}$, an occluded liquid with a volume of $\approx 10^{4} \mu \mathrm{m}^{3}$, undergoing a tension of $\approx-80 \mathrm{MPa}$, can sustain such a high superheated state during $10^{7}$ seconds. A first consequence is that the half-life duration of metastability of such a system, one order of magnitude larger than one million years, is quite relevant to geological timescales. Secondly, it has been recently indicated that the changes in water properties related to superheating significantly influence the rock-water-gas equilibria as soon as the tensile strength of the liquid reaches $-20 \mathrm{MPa}^{1}$. Thus, our data prove that the metastability of micrometric fluid volumes is indeed a process of major geochemical importance.

As a conclusion, this paper, together with a companion one, firstly highlights that fluid inclusions are very adapted to the experimental study of superheated solutions at the $\mu \mathrm{m}$ - to mm-scale, both from the metastable intensity and kinetics points of view. In addition, we previously showed that aqueous 
fluids appear to superheat easily since all the 937 inclusions studied, containing pure water and various aqueous solutions, displayed superheating, some to very high degrees up to $-100 \mathrm{MPa}$. The major point of this paper is to give the first quantitative proof that microvolumes of highly superheated water can sustain this stretched state for a very long time, infinite at the human scale. The fact that superheating modifies both the thermodynamic and solvent properties of water has already been assessed ${ }^{15,24-25}$. It is here illustrated that such changes can persist over geologically-relevant timelengths, large enough for superheated fluids to become a possible controlling parameter of the evolution of natural systems.

\section{Acknowledgements}

This work has received financial support from the French Agency for Research (Agence Nationale de la Recherche), grant SURCHAUF-JC05-48942 (grant responsible: L. Mercury) and from Russian Fund of Basic Investigations, grant 06-05-64460 (grant responsible: K. Shmulovich). Finally, Jean-François Lenain is greatly acknowledged for his advices and control of the statistical treatment of the data.

\section{References}

1. Pettenati M., Mercury L. and Azaroual M. (2008) Capillary geochemistry in non-saturated zone of soils. Water content and geochemical signatures. Applied Geochem. 23(12), 3799-3818.

2. Meslin P.Y., Sabroux J.-C., Berger L., Pineau J.-F., and Chassefière E. (2006) Evidence of 210 Po on martian dust at meridiani planum. J. Geophys. Res. 111, art. E09012, 14 p.

3. Jouglet D., Poulet F., Milliken R.E., Mustard J.F., Bibring J.P., Langevin Y., Gondet B., and Gomez C. (2007) Hydration state of the Martian surface as seen by Mars Express OMEGA: 1. Analysis of the 3 $\mu \mathrm{m}$ hydration feature. J. Geophys. Res. 112, art. E08S06, $20 \mathrm{p}$.

4. Ramboz C. and Danis M. (1990). Superheating in the Red Sea? The heat-mass balance of the Atlantis II Deep revisited. Earth Planet. Sci. Lett. 97, 190-210.

5. Shmulovich K.I. and Graham C.M. (2004). An experimental study of phase equilibria in the systems $\mathrm{H}_{2} \mathrm{O}-\mathrm{CO}_{2}-\mathrm{CaCl}_{2}$ and $\mathrm{H}_{2} \mathrm{O}-\mathrm{CO}_{2}-\mathrm{NaCl}$ at high pressures and temperatures $\left(500-800^{\circ} \mathrm{C}, 0.5-0.9 \mathrm{GPa}\right)$ : geological and geophysical applications. Contr. Mineral. Petrol. 146, 450-462

6. Wagner W. and Pruss A. (2002) The IAPWS Formulation 1995 for the Thermodynamic Properties of Ordinary Water Substance for General and Scientific Use. J. Phys. Chem. Ref. Data 31, 2, 387-535.

7. Kiselev S.B. and Ely J.F. (2001) Curvature effect on the physical boundary of metastable states in liquids. Physica A 299, 357-370.

8. Speedy R.J. (1982) Stability-limit conjecture. An interpretation of the properties of water. J. Phys. Chem. 86, 982-991. 
9. Debenedetti P.G. and D'Antonio M.C. (1986) On the nature of the tensile instability in metastable liquids and its relationship to density anomalies. J. Chem. Phys. 84(6), 3339-3345.

10. Poole P.H., Sciortino F., Essmann U. and Stanley H.E. (1992) Phase behaviour of metastable water. Nature $360,324-328$

11. Mishima O. and Stanley H.E. (1998) The relationship between liquid, supercooled and glassy water. Nature 396, 329-335.

12. Sastry S., Debenedetti P.G., Sciortino F and Stanley H.E. (1996) Singularity-free interpretation of the thermodynamics of supercooled water. Phys. Rev. E 53, 6144-6154.

13. Stanley H.E. and Teixeira J. (1980) Interpretation of the unusual behavior of $\mathrm{H}_{2} \mathrm{O}$ and $\mathrm{D}_{2} \mathrm{O}$ at low temperatures: tests of a percolation model. J. Chem. Phys. 73 (7), 3404-3422.

14. Shmulovich K.I., Mercury L., Thiéry R., Ramboz C. and El Mekki M. (2008) Experimental superheating of water and aqueous solutions. Geochim. Cosmochim. Acta, Submitted. Shmulovich K.I. (2008) Longliving superheated aqueous solutions: experiment, thermodynamics, geochemical applications, this volume.

15. Mercury L., Azaroual M., Zeyen H., and Tardy Y. (2003) Thermodynamic properties of solutions in metastable systems under negative or positive pressures. Geochim. Cosmochim. Acta 67, 17691785.

16. Span R. and Wagner W. (1993) On the extrapolation behavior of empirical equation of state. Int. J. Thermophys. 18(6), 1415-1443.

17. Roedder E. (1967) Metastable superheated ice in liquid-water inclusions under high negative pressure. Science 155, 1413-1417.

18. Green J.L., Durben D.J., Wolf G.H. and Angell C.A. (1990) Water and solutions at negative pressure: Raman spectroscopic study to -80 Megapascals. Science 249, 649-652.

19. Zheng Q., Durben D.J., Wolf G.H. and Angell C.A. (1991) Liquids at large negative pressures: water at the homogeneous nucleation limit. Science 254, 829-832.

20. Alvarenga A.D., Grimsditch M., and Bodnar R.J. (1993) Elastic properties of water under negative pressures. J. Chem. Phys. 98, 11, 8392-8396.

21. Ramboz C., Orphanidis E., Oudin E., Thisse Y. and Rouer O. (2008). Metastable fluid discharge by the Atlantis Deep submarine geyser: the heat-mass balance of the stratified lower brine revisited in the light of new fluid inclusion data. This volume.

22. Debenedetti P.G. (1996) Metastable liquids. Concepts and principles. Princeton University Press, Princeton, $411 \mathrm{p}$.

23. Takahashi M., Izawa E., Etou J. and Ohtani T. (2002) Kinetic characteristic of bubble nucleation in superheated water using fluid inclusions. J. Phys. Soc. Japan 71(9), 2174-2177. 
24. Mercury L., Pinti D. L., and Zeyen H. (2004) The effect of the negative pressure of capillary water on atmospheric noble gas solubility in ground water and palaeotemperature reconstruction. Earth \& Planetary Sci. Lett. 223, 147-161.

25. Lassin A., Azaroual M., and Mercury L. (2005) Geochemistry of unsaturated soil systems: aqueous speciation and solubility of minerals and gases in capillary solutions. Geochim.Cosmochim. Acta 69, 22, $5187-5201$. 